\title{
THE PROCESS OF SCHEMA EMERGENCE: ASSIMILATION, DECONSTRUCTION, UNITIZATION AND THE PLURALITY OF ANALOGIES
}

\author{
CHRISTOPHER B. BINGHAM \\ The University of North Carolina, Chapel Hill \\ STEVEN J. KAHL \\ Dartmouth College
}

\begin{abstract}
Schemas are a central concept in strategy and organization theory. Yet, despite the importance of schemas, little is known about how they emerge. Our in-depth historical analysis of how groups in the life insurance industry developed their schema for the computer from 1945-1975 addresses this gap. We identify three key processesassimilation, deconstruction, and unitization-that collectively explain and resolve an inherent tension related to schema emergence: how to make the unfamiliar familiar but conceptually distinct. We also find that each process relates to analogical transfer, but in a more pluralistic and dynamic way than the existing literature describes. Broadly, these findings have important implications for organizational change and managerial cognition.
\end{abstract}

A long-standing finding in strategy and organization theory is that managing environmental change is difficult. Research suggests that it may not be an environmental change per se that creates difficulties; instead, it may be executives' cognitive assessments of the change (Kaplan, 2008b). Environmental changes, such as technological innovations, make it challenging for organizations to effectively engage in coordinated action since the meaning of the innovations may be unclear (Kaplan \& Tripsas, 2008; Tripas \& Gavetti, 2000).

Research suggests that schemas are central to the ways organization members deal with these cognitive challenges. Schemas are defined as knowledge structures that contain categories of information and relationships among them (Dane, 2010; DiMaggio, 1997; Elsbach, Barr, \& Hargadon, 2005; Fiske \& Dyer, 1985; Gick \& Holyoak, 1983). Schemas are important because they help give meaning to envi-

Authors are listed alphabetically. We appreciate the generous support of the Kenan-Flagler Business School at UNC and the University of Chicago Booth School of Business, and the research assistance of Erin Norwood, Neil Levy, and Daimon Lockett. We also thank multiple individuals for their very helpful comments, including Steve Barley, Kathy Eisenhardt, Anita McGahan, Woody Powell, Violina Rindova, Mary Tripsas, and JoAnne Yates; seminar participants at MIT, Michigan, Northwestern, Stanford, Wharton, the University of Chicago, the University of Illinois, and the University of Maryland; our anonymous reviewers; and our editor, Andy Van de Ven. ronmental changes and so help stimulate and shape action (Elsbach et al., 2005; Nadkarni \& Narayanan, 2007). Traditionally, scholars have examined schemas for their impact (Schminke, Ambrose, \& Noel, 1997) and for their change (Elsbach et al., 2005) or structural attributes, such as size, complexity, or focus (Dane, 2010; Nadkarni \& Narayanan, 2007). However, although organization scholars have continued to call for research that moves beyond understanding the content of cognitive concepts such as schemas (Gavetti, Levinthal, \& Rivkin, 2005), explicit research on how schemas emerge is limited.

Existing organizational and psychology studies provide some insight into the question of how schemas come to exist. The innovation literature in organization studies states that innovations are assessed by applying existing cognitive constructs of a preceding technology, often by invoking analogies (Benner \& Tripsas, 2012; Clark, 1985; Hargadon \& Douglas, 2001; Rindova \& Petkova, 2007). Work in psychology more explicitly explains how analogical transfer can help create new schemas by mapping categories and relations from an existing schema to a new one (Gentner, 1983; Gick \& Holyoak, 1983). But this application of analogies only helps explain how a new schema is made familiar; it does not address how it then becomes conceptually distinct from an existing schema. So, although it appears likely that analogies play a role in the formation of a collective schema, no studies explicitly address how this may occur and what else, if anything, is needed to establish a new schema. 
The purpose of this study is to address this gap. Specifically, we ask, How does a new collective schema emerge over time? Addressing this question is important as it enhances understanding of how cognition influences organizational behavior. Through content analysis, we empirically study how, from 1945 through 1975, groups in the life insurance industry developed a new schema for what came to be known as "the business computer."

A central contribution of this study is an emergent theoretical framework for schema emergence. We identify three processes and develop propositions about their effect. First, schema emergence begins with assimilation. We find that insurance groups faced two distinct analogies for the computer schema but assimilated the familiar one much more than the novel one. High assimilation of the familiar analogy with the existing schema helped the new technology gain traction; however, low assimilation of the novel analogy made innovative aspects of computers less salient. Deconstruction is a second key process that facilitates differentiating an assimilated schema to help create a new schema. As insurance firms continued to use the new computer technology, the categories and relations of the familiar analogy became more general and less valid, whereas the categories and relations of the marginal, novel analogy became more specific and more valid. Finally, we find support for unitization as a process related to solidifying the new schema. Data reveal that categories and relations related to the novel analogy increasingly connected to each other so that they became a conceptually distinct stand-alone cognitive unit.

More broadly, our study contributes to research on organizational change by resolving a conundrum related to the process of emergence-how to manage the simultaneous existence of two inconsistent states, familiarity and novelty. Our study also contributes to research on managerial cognition by uncovering a pluralistic view of analogies that develops a more dynamic view that is relevant at collective (versus individual) levels of analysis and that underscores not only the number of analogies, but also their nature and ongoing interplay.

\section{THEORETICAL BACKGROUND}

As scholars become increasingly interested in innovation and change, they have begun to characterize the cognitive concepts that influence how market participants interpret their environment. This research often highlights schemas, defined as representations of the categories associated with a concept as well as their relations (Dane, 2010; Hargadon \& Fanelli, 2002). As such, schemas act as cognitive frameworks that simplify information processing (DiMaggio, 1997). They enable firm leaders to interpret their environment and so promote efficiency as ongoing activities are cast into relatively stable patterns (Misangyi, Weaver, \& Elms, 2008). ${ }^{1}$

Existing research in organizational studies addresses several key issues related to schemas, such as their structure, use, or change. For example, some studies focus on complexity (Eden \& Shani, 1982; Nadkarni \& Narayanan, 2007). Complexity refers to both the number of distinct categories in a schema as well as the degree of connectedness (i.e., number of relations) among those categories (Walsh, 1995). Theorists have argued that complex schemas allow organization members to accommodate a greater variety of distinct strategy solutions in decision making (Nadkarni \& Narayanan, 2007). Other studies have focused on schema change. They suggest that with the accumulation of experience and understanding, a given schema will become more stable because the categories and relations comprising schemas become harder to change (Dane, 2010; Fiske \& Taylor, 1984). Yet, although this research has been explicit about the definitions of schemas, as well as about their structure, use, change, and relevance, it has been far less explicit about schema emergence.

Although organizational studies have not directly addressed schema emergence, they have focused on the challenges of recognizing something new. Radical innovations are difficult to understand because they introduce new categories and relations that are not present in existing schemas (Rindova \& Petkova, 2007). To overcome this incongruity, existing schemas are often invoked to define and give meaning to innovations. Thus, Clark (1985) observed that initially the radically

\footnotetext{
${ }^{1}$ The schema concept is related to a variety of cognitive concepts, including frames, industry recipes, categories, knowledge structures, dominant logics, and interpretive schemes. Importantly, many of these concepts also share definitional underpinnings with the schema concept. For example, several scholars use the term "frame" (Benford \& Snow, 2000; Kaplan, 2008b; Kaplan \& Tripsas, 2008), which relies on and explicitly references Goffman's original conceptualization of frames as "schemata of interpretation" (1974: 21). Other organizational scholars focus on interpretive schemes, which are defined as "cognitive schemata that map experience of the world" (Bartunek, 1984: 355), or on "knowledge structures," a term used interchangeably with schema (Walsh, 1995: 285). Thus, we focus on the schema concept not only because it is central in the organizations literature but also since other frequently invoked cognitive concepts share conceptual underpinnings with it.
} 
new automobile was described as a "horseless carriage." Organizational research often invokes analogies as a cognitive mechanism to interpret the new, such as new products (Hargadon \& Sutton, 1997; Rindova \& Petkova, 2007), new strategies (Gavetti et al., 2005), new problems (Schon, 1993), and new institutional designs (Etzion \& Ferraro, 2010). However, although these empirical studies provide much understanding about the value of analogical transfer in recognizing and processing the new, they do not directly address how analogies influence schema emergence.

Fortunately, research in psychology provides some insight about how analogies can contribute to developing a new schema. This work defines analogies in terms of mapping the relations and/or categories from an existing schema to a novel situation (Gentner, 1983; Gick \& Holyoak, 1983; Holyoak \& Thagard). For example, Gentner and Markman (1997) explained Kepler's use of an analogy from a light schema to generate a planetary schema. The light schema consisted of the categories "light" and "objects," connected through the relation "illumination," whereas the planetary schema consisted of the categories "sun" and "planets," connected through the relation "motion." Kepler's analogy drew attention to the similarity in the relations, implying that just as light illuminates farther objects more weakly, the sun moves planets farther away more weakly. Consequently, analogies can help create new schemas by introducing new categories and relations through this mapping process. Experimental evidence (Gick \& Holyoak, 1983; Novick \& Holyoak, 1991; Schustack \& Anderson, 1979) and computational analysis (Winston, 1980) have shown support for the use of analogies to create new schemas.

Although linking analogies to the emergence of a new individual-level schema is generally supported in psychology, unresolved issues remain regarding how a collective-level schema emerges. First, schema emergence in organizations is likely more complicated and dynamic than psychology theory suggests. Psychology studies on schema emergence generally have focused on lab studies in which individuals face clear, concise and concrete analogs that directly map to target problems (Gick \& Holyoak, 1983). Decision makers in organizations rarely face such clear-cut situations and solutions. Moreover, for a schema to emerge through analogical transfer, many subjects require an explicit hint to help them realize the correspondence between the elements of a source analog and those of a target (Novick \& Holyoak, 1991). It is hard to imagine such hints could be provided in an organization.
Second, the nature of analogies differs greatly at the organizational level. Most studies in psychology have shown that individuals usually draw on one analogy at a time to generate a new schema (for an exception, see Loewenstein and Gentner [2005]). Serial processing of analogies takes place, wherein each is not in direct competition with another (Gick \& Holyoak, 1983). By contrast, in organizations individuals may face multiple competing analogies that must be processed simultaneously, not serially. These analogies may be of varying familiarity - some less novel and some more novel-thereby making it less clear which analogies might be adopted and why. Together, these points suggest that existing psychological theory for schema emergence at the individual level may be imprecise for portraying schema emergence at the collective level.

Moreover, the nature of an organization complicates understanding of how a collective (versus individual) schema might emerge. On the one hand, it seems likely that the number of potential relationships between categories might increase combinatorially with the number of new categories added over time by different users, thereby permitting a vast and unpredictable range of different potential schema structures to emerge. On the other hand, having a large number of relations and categories may be insufficient to guarantee schema emergence; many of the relations or categories may be less relevant or salient. Indeed, it may be the case that certain emergent categories and relations can inhibit schema formation by pushing out other important categories and their relations. The existing organizational literature on categories provides some tentative support for these arguments. It highlights the importance of differentiating categories to establish a distinct category (Hannan, Polos, \& Carroll, 2007). Yet, because this work has focused on only one component of schemas, categories, and overlooked relations among categories and analogies, it is not clear if what happens at the category level happens at the schema level.

Finally, analogical transfer alone is insufficient to explain the schema emergence process. Analogical transfer helps explain the initial recognition and processing of new schemas through the application of existing schemas, yet it does not explain how these new schemas then become differentiated from the existing schemas. In fact, the existing schemas may come to dominate the new ones (Rindova \& Petkova, 2007), preventing the new from developing into distinct cognitive units. Overall, although the existing literature suggests that the development of a new schema involves the identification of new categories and relations, there is little in-depth understanding about how the new 
schema becomes distinct and persists as an independent cognitive structure. In this study, we seek to provide a more complete account of schema emergence.

\section{DATA AND METHODS}

Given the general lack of research on schema emergence, we combined theory elaboration (Lee, 1999) and theory generation (Eisenhardt, 1989) in our analysis. Thus, we were aware of the existing literature on schemas and examined data for the relevant constructs, including categories and relations among categories. But we also looked for unexpected types of processes by which those categories and relations developed over time and became institutionalized as a new schema.

\section{Case Selection and Data Sources}

We examined how groups in the life insurance industry developed a new schema to interpret what became know as business computers from 1945 to 1975. Today, the term "business computers" indicates the technology used to process and manage mainstream corporate transactions (as opposed to computational computers, which were originally used in the military). Individuals in the insurance industry used business computers to process and issue new applications and to manage premium payments (Yates, 2005). As a radical new technology, computers did not exist in a previous schema and offer an opportunity to examine how a new schema gets developed.

We focused on the insurance industry for several reasons. First, as Yates (2005) noted, insurance was one of the first and largest industries to use computers. To provide an understanding of the general commercialization of computers, we must comprehend how those in the insurance industry interpreted it. Second, the large financial and organizational commitment to purchase computers left a rich archival record of public discussion. Last, the discourse about computers concentrated among certain occupational groups and trade associations (Yates, 2005): the Society of Actuaries (SOA), Life Office Management Association (LOMA), and Insurance Accountant and Statistical Association (IASA). SOA is the main professional society for actuaries. LOMA and IASA focus on general issues related to insurance, and in particular, the use of office technology, and had representatives from accounting, administration, and systems work. Thus, the collective schema represents what these key insurance groups used to evaluate the new technology and allows us to analyze changes within it.
Consequently, our archival efforts focused on the proceedings of these three associations. These associations created committees to investigate computers, held conferences, and in SOA's case, distributed an influential report on computers before their commercial release. The proceedings also included detailed discussions regarding use or planned use of computers. In many cases, the discussions provide detailed procedures as to how systems worked, purchasing and evaluating computers, and other important topics such as organizational and career concerns of computer-related professionals. We collected a total of 399 articles, reports, and books from the period $1945-75 .^{2}$ Our collection includes information available in 1945 , which provides a sense of the existing schema for earlier office technologies and initial interpretations of what came to be known as "the computer" before it was actually used. Although the schema continues to evolve today, we finish our collection period in the mid 1970s because by 1975 the computer schema had fully emerged as an independent knowledge structure.

\section{Coding Methodology}

We take written discourse to represent cognitive schemas (Barr, Stimpert, \& Huff, 1992; Tsoukas, 2009). Methodologically, we utilized primary reports to identify and measure changes in the collective schema. Defining schemas in terms of their categories and relations entails identifying the various categories and how they are related within each text. Grammatically, we interpreted nouns as categories and verbs as relations, which required capturing all of the nouns in a text as well as the verbs and the nouns to which the verbs connected.

Since we were interested in relational structure as well as categories, we adopted Carley's (1993, 1997) cognitive mapping approach to measure cognitive schemas. Cognitive mapping is a form of content analysis that involves processing sentences in a text to isolate categories and their relational structure. We scanned each original document and used optical character recognition (OCR) technology to convert the images to text files. ${ }^{3}$ We used

\footnotetext{
${ }^{2}$ As noted, the SOA developed important early documents, such as a report on computers, which we include in our study. But because since we were interested in business computers, and actuaries also worked on computational computers, the bulk of the articles throughout this time period come from IASA and to a lesser extent LOMA. Actuaries were well-represented presenters at the IASA and LOMA meetings.

${ }^{3}$ Eleven documents could not be scanned or yielded
} 
Carley and colleagues' Automap software to identify the instances of all the words and their parts of speech. Given our interest in schemas, we focused on the verbs and nouns in our texts. An important part of this process involves considering which nouns and verbs to capture (Carley, 1993). We focused on nouns and verbs that denoted what came to be known as computers and their operations, choosing to exclude extraneous information introducing the topic or describing a company. We processed the nouns and verbs separately so the identified categories were not dependent upon the relational structure. Although the software was capable of mapping the full relations, we found the texts written in a style that made it difficult to accurately capture relationships in an automated fashion. Therefore, with the generated list of nouns and verbs, we read through each piece of text to capture what categories each verb connected.

To get a sense of the process, consider the following statement from an article presented at an association meeting: "The cards are then mechanically calculated and punched with the unpaid number of weeks and the unpaid portion of the first year's premium and commission to be withdrawn" (Beebe, 1947: 191). Under our procedure, the categories include the nouns "cards," "unpaid number of weeks and portion of the premium," and "the unpaid number of weeks and portion of the commission." The relations include the verbs "calculate" and "punch." The full relational statements connect "card" with each of the two data elements. We coded each verb in its present tense, simple form. For example, "calculated" was coded as "calculate." Nouns, however, were captured exactly as represented in a text to indicate any changes to them over time, which served to identify new emergent concepts. We debated two primary ways to code frequency-indicating each occurrence or absence in a text (Carley, 1993). Since many of these texts were procedural, they had multiple occurrences of the same categories and relations. Consequently, we only identified whether a category or relation was present in a text. We completed this procedure for each text for each year, generating 4,330 unique categories and 451 unique relational verbs. $^{4}$

OCR results too poor in quality to use. For these cases, we did not use the Automap software but coded category and relational structure by reading through the texts.

${ }^{4}$ The number of categories is high because we coded categories at the lowest level of analysis-that is, exactly how the terms were presented (e.g., IBM_650 or IBM_650_digital_computer). The number of relations is lower because we focused only on relational verbs that
The collective schema for each year represents the aggregate of the texts. Appendixes A and B summarize the most frequently occurring categories (Appendix A) and relations (Appendix B) for the collective computer schema from 1947 (corresponding to the first discussion of computers) to 1975. To avoid the idiosyncrasies of year-to-year fluctuation in the level of discourse, we collapse the initial discussions of computers prior to commercial release for the insurance industry in 1954 together (1947-54) and then group them by threeyear increments. Each cell represents the total number of articles that used a particular category or relation. These frequency counts show how certain categories and relations became more or less prevalent over time and so help us to assess schema emergence. Finally, it should be noted that throughout our narration we try to use the terms used at the time but often use the term "computer." By "computer" we mean "business computer." The use of the term is not intended to reify computers. Although Appendix A shows how the term "computer" was indeed used frequently early on, it was not so much the term "computer" as it was its relations with other terms that helped develop and change its meaning.

Following Kaplan and Tripsas's (2008) call for more historical work within the cognitive processes of technological change, we also extend Carley's (1997) content analysis method by considering the historical context and the actual use of computers. Our analysis of the association materials reveals the importance of technological changes in computers, how the insurance industry used them, and broader trends about computer technology, such as the development of management information systems (MIS) in the late 1960s and 1970s. Therefore, we supplement our analysis of association proceedings with historical analysis of technological changes, research on the life insurance industry's uses of computers (Yates, 2005), and the general history of these broader movements (Haigh, 2001).

\section{HISTORICAL CONTEXT}

Life insurance firms provide policy holders coverage against potential loss in exchange for premiums. Beyond the actuarial and investment analysis,

connected categories. Given the subjectivity of this process, we randomly selected ten articles and had two graduate students not associated with the project code each. Ninety-two percent of the categories, relations, and relational connections of one coder were included in our coding collection, and 88 percent of the other coder's. 
much of the work in insurance firms is routine and clerical: preparing and processing policy records, determining premiums paid, dividends, and agent commissions, notifying policy holders about and collecting premium payments, and carrying out accompanying accounting procedures to record these transactions (Adams, 1946). Historically, insurance firms invested heavily in clerical workers and technology to efficiently manage these policy and accounting processes (Yates, 1989). By the 1940s, the technology included a combination of business machines-tabulating machines, sorters, verifiers, calculators, and addressing machines-to sort and calculate information represented as punched holes in cards, called "punch cards." These punch cards became the record on which policy and accounting information was stored. As IBM historians have noted, "Insurance companies were among the largest and most sophisticated business users of punched-card machines in the late 1940s and 1950s" (Bashe, Johnson, Palmer, \& Pugh, 1986: 176-177).

During World War II, industries experienced a clerical labor shortage, exacerbated in the insurance business by a postwar life insurance boom (Bureau of Labor Statistics, 1955). As a result, the insurance industry became increasingly interested in new technologies to aid in information processing. One promising, radically new technology that emerged from the war was what became known as computers. After the war, technology manufacturers, in search of a commercial market, began developing what became known as business computers, which no longer simply did computational work but also managed business processes such as processing premiums. For the insurance industry in particular, the process of adopting this new technology involved developing interpretations of what computers were-that is, a collective schema that captured an understanding about computers.

Our historical analysis surfaced three distinct temporally phased processes shaping the insurance firms' development of the computer schema: assimilation, deconstruction, and unitization. Unexpectedly, we found that each process related to analogical transfer, but in a more nuanced and dynamic way than what is described in the psychology literature. In the following sections, we discuss each process in our case and then generate propositions.

\section{THE ASSIMILATION PROCESS}

The starting point of an emergence process is cognitive recognition of a new object, in this case, the computer. We call this recognition process assimilation as it involves incorporating a new situ- ation into an existing schema. Scholars have argued that making related analogies between past technological solutions and a new technology helps in this assimilation process because it increases the recognition and ultimately the legitimization of the new technology (Hargadon \& Sutton, 1997; Rindova \& Petkova, 2007). Our data, however, reveal that although analogies help initiate the recognition process, they can have negative effects on schema emergence by pushing the categories and relations that capture what is truly unique about the new technology into the periphery of the schema. Specifically, we found that prior to the adoption of computers in 1954, individuals in insurance companies faced two distinct analogies for the new technology: (1) "machine" and (2) "brain." They largely adopted the machine analogy by assimilating its categories and relations directly into their existing schema for office machines. But this came at the cost of pushing out the analogy with the human brain that emphasized the novelty and potentiality of the new technology.

Methodologically, capturing this assimilation process requires identifying the different analogies, the existing schema for current office technology, and how the latter was used to evaluate the analogies. Yates's (2005) historical analysis reveals insurance firms began to seriously investigate and publicly discuss what became known as business computers in the mid 1940s. The initial discourse included presentations at conferences from insurance and computer manufacturers, commissioned reports to study the application of computers in the industry, and even books on the subject.

Therefore, our initial analysis focused on the time these discussions started through the initial adoption, the period 1945-54. We identified 67 texts, 41 addressing existing office technologies, such as tabulating machines, used to process insurance work. We used these 41 texts to develop the existing schema. The following passage describing Prudential's use of various tabulating machines to prepare important documents illustrates the thencurrent thought about office technology:

From approved new business applications, policy writing and beneficiary cards are key punched and verified. The policy writing cards are mechanically sorted and matched with master cards (by collator) to insure the accuracy of the age, kind, premium and amount of insurance in each case. The policy writing and beneficiary cards are next mechanically merged in policy number order and used to write the policies on a bill feed tabulator. After completing the listing of the agents' register sheets, the new business, reinstatement and life transfer cards are 
reproduced to in-force file cards. (Beebe, 1947: 191-192)

From a schema perspective, this passage shows the focus on the categories of the punch cards as the primary unit of information and the machine doing the work, and the transaction-oriented relations through which these cards were processed, manipulated, and calculated.

The remaining 26 texts demonstrated two dominant analogies for the new technology: one comparing the computer to a brain and the other to a machine. Edmund Berkeley (see Yates [1997] on Berkeley), an executive from Prudential who had extensive interactions with computer manufacturers, discussed the computer as a "mechanical brain" and in 1949 developed the brain analogy in his popular book, Giant Brains. "Recently," he stated, "there has been a good deal of news about strange giant machines that can handle information with vast speed and skill. They calculate and they reason.... These machines are similar to what a brain would be if it were made of hardware and wire instead of flesh and nerves" (Berkeley, 1949: 1). The brain analogy thus developed the interpretation of the computer as a machine that makes decisions through the use of such relations as "solve," "think," and "examine."

Whereas Berkeley's brain analogy focused on the new technology's ability to think and reason much like a human, others in the industry developed a different analogy. In 1952, the Society of Actuaries formed a Committee on New Recording Means and Computing Devices that issued a major and influential report, and both the IASA and LOMA hosted panels at their conferences about potential use of computers. Unlike Berkeley's work, these machinecentered reports characterized computers as an electronic version of existing technology, often using the analogy "information processing machine" or "data processing machine" to describe the new technology. The 1952 Society of Actuaries' report stated:

These new machines have been called computers because they were developed primarily for mathematical work. It is a mistake, however, to think of them today as purely computing machines capable only of a large amount of arithmetic. In recent years, some very important improvements have converted them into machines capable of a wide variety of operations. Nowadays we must think of them as information processing machines with computing representing just a part of their total capabilities. (Davis, Barber, Finelli, \& Klem, 1952: 5)

In contrast to the brain analogy, the machine analogy developed the interpretation of a computer as a machine that processes transactions through the use of such relations as "merge," "punch" and "match."

The analogies also varied in the level of assimilation with the existing schema for office technology. We measure the extent of assimilation by the degree to which the categories and relations of the analogy are the same as those of the existing schema. Higher levels of assimilation correspond to sharing the same categories and relations. To assess the degree of assimilation, we identified the categories and relations for the existing brain schema and the machine analogies using the aforementioned coding procedure. This generated 334, 322, and 152 unique categories and 103, 83, and 77 unique relations for the existing schema and the machine and brain analogies, respectively. Of the total categories in the preexisting schema, 35 percent overlapped with the categories in the machine analogy, versus 12 percent for the brain analogy. Likewise, of the total relations in the existing schema, 50 percent overlapped with those in the machine analogy, versus 26 percent for in the brain analogy.

The sharing of categories and relations is not a complete measure of assimilation; however, it is possible that the shared categories and relations are not part of the central schema of interest or are not very meaningful. Table 1 addresses this issue by comparing which categories and relations associated with the machine or the brain analogy are shared with the central categories and relations of the existing schema. We define "central" in terms of the high-frequency categories and relations in the existing schema. Table 1 shows a concentration around categories such as "clerk," "punch card," "policy," "tabulator," and "machine." The relations between these categories centered on creating or inputting information on cards through the action of a "punch," processing punch cards ("sort," "file," "merge," "matching"), and writing output ("print," "list," “post").

Table 1 demonstrates the strong similarities between the existing schema and the machine analogy among these core categories and relations. Relationally, the machine analogy focused on similar kinds of transaction-oriented actions: entering information ("read," "punch in"), processing information ("sort"), and writing results ("write"). In contrast, approximately 50 percent of the core categories and relations of the existing schema are not used with the brain analogy. The brain analogy uses different categories and relations. Although there are similarities with the existing schema and the machine analogy, such as "data," "computer," and "add," the brain analogy contains mainly new 
TABLE 1

Comparing Categories and Relations of the Existing Schema with the Analogies, 1945-54

\begin{tabular}{|c|c|c|c|}
\hline $\begin{array}{c}\text { Schematic } \\
\text { Element }\end{array}$ & $\begin{array}{c}\text { Preexisting } \\
\text { Schema }\end{array}$ & $\begin{array}{l}\text { Computer as } \\
\text { Machine }\end{array}$ & $\begin{array}{c}\text { Computer as } \\
\text { Brain }\end{array}$ \\
\hline \multicolumn{4}{|l|}{ Category } \\
\hline Machine & 37 & 15 & 5 \\
\hline Card & 34 & 11 & 1 \\
\hline Punch card & 31 & 13 & 1 \\
\hline Clerk & 28 & 11 & 1 \\
\hline Information & 22 & 16 & 5 \\
\hline Home office & 21 & 7 & 0 \\
\hline Policyholder & 17 & 7 & 1 \\
\hline Premium notice & 17 & 2 & 1 \\
\hline Policy & 17 & 7 & 1 \\
\hline Premium & 16 & 4 & 0 \\
\hline File & 16 & 9 & 2 \\
\hline Tabulator & 16 & 4 & 0 \\
\hline Addressograph & 15 & 2 & 0 \\
\hline Agent & 15 & 3 & 0 \\
\hline Collator & 15 & 1 & 0 \\
\hline Master card & 15 & 3 & 0 \\
\hline Total & 15 & 1 & 0 \\
\hline Notice & 14 & 2 & 0 \\
\hline Sorter & 12 & 1 & 0 \\
\hline Stub & 12 & 2 & 0 \\
\hline \multicolumn{4}{|l|}{ Relation } \\
\hline Punch & 33 & 2 & 0 \\
\hline File & 30 & 4 & 1 \\
\hline Check & 30 & 7 & 3 \\
\hline Sort & 27 & 8 & 1 \\
\hline Prepare & 26 & 4 & 0 \\
\hline Reproduce & 25 & 3 & 0 \\
\hline List & 18 & 0 & 1 \\
\hline Pull & 16 & 0 & 0 \\
\hline Compare & 15 & 4 & 2 \\
\hline Write & 14 & 4 & 4 \\
\hline Post & 14 & 4 & 0 \\
\hline Verify & 14 & 2 & 1 \\
\hline Merge & 13 & 4 & 0 \\
\hline Run through & 13 & 4 & 0 \\
\hline Add & 12 & 4 & 3 \\
\hline Tabulate & 12 & 2 & 0 \\
\hline Calculate & 12 & 5 & 2 \\
\hline Match & 11 & 3 & 0 \\
\hline Enter & 11 & 2 & 1 \\
\hline Total articles & 41 & 21 & 5 \\
\hline
\end{tabular}

categories and relations associated with decision making: categories, such as "problem" and "operation," and relations, such as "solve," "examine," and "think." Hence, data show that the machine analogy was well assimilated, but the brain analogy was not.

The insurance industry quickly converged on the machine analogy and largely characterized computers as such. Of the 26 texts that discussed computers from 1947 to 1954,21 used the machine analogy. Many rejected the brain analogy outright.
E. F. Cooley of Prudential Life argued this: "I might use the term 'giant brains' to tie in my subject with the more or less popular literature on this subject. But I hate to use that term since there are false implications in it, implications that these machines can think, reason and arrive at logical conclusions, and I don't agree that this is true" (Cooley, 1953: 355). Computer manufacturers also emphasized the machine analogy in the 32 texts presented within these associations during this time period. IBM even adopted the label "electronic data processing machine" to describe a computer, which quickly became common nomenclature.

When insurance firms started purchasing computers in 1954, they began using them in a way that was consistent with the transaction and machine view. A series of surveys conducted by the Controllership Foundation in 1954-57 revealed life insurance firms converted existing office applications, such as premium billing and accounting, to computers, rather than create new decision-oriented business processes. Yates (2005) also noted how this incremental, machine-like use of computers persisted throughout the 1950s into the 1960s.

A key question is how assimilation of analogies relates to schema emergence. Empirical research suggests the use of analogies is especially likely when the new is sufficiently different and challenging (Gick \& Holyoak, 1983), as it is in the case of introduction of a new technology such as computers. Specifically, analogies help assimilate the unfamiliar by mapping categories and relations to existing schemas (Gentner, 1983; Gick \& Holyoak, 1983; Holyoak \& Thagard, 1989). Although other studies have also noted how what is new may be assimilated into what is known (e.g., Clark, 1985), our study reveals how analogies are assimilated. These analogies vary in the level to which they are assimilated depending on how many categories and relations they share with an existing schema. The machine analogy was assimilated into the existing schema more than the brain analogy because it shared more of the core categories and relations of the existing schema.

A related question is why high levels of assimilation occur. From psychology, Gentner and Markman (1997) argue that the degree of alignment between an existing schema and an analogy shapes the processing of the analogy. The higher the alignment, the more important and salient overlapping categories or relations become. In our empirical context, the existing schema was well established and centered around categories and relations that aligned more with the machine analogy than the human-based categories and relations of the brain analogy. Indeed, insurance firms had been long- 
time users of tabulating machines and had developed common routines and uses for these machines (Yates, 2005). These common uses helped establish consensus around transaction-oriented relations and categories such as clerks, machines, and punch cards (see Table 1). Moreover, the machine analogy reflected a growing interest in office automation and gained increased legitimacy because the committees who were granted authority to learn about the new technology and report back to the broader associations also endorsed this interpretation. ${ }^{5}$ For example, as noted earlier, the influential SOA 1952 report adopted the machine analogy. Overall, greater alignment between the existing schema and the machine analogy led to higher levels of assimilation of the machine analogy.

In summary, an implication of our analysis is that a familiar analogy helps an emergent schema initially gain traction at the cost of pushing aside the emerging schema's differentiating categories and relations. In this study, the more novel decision-making categories and relations linked with the brain analogy appeared less frequently (were less central) as the emerging schema focused more on the transaction-processing machine-like qualities of the machine analogy. Collectively, these observations lead to our first proposition:

Proposition 1. The more an analogy's categories and relations assimilate into an existing schema, the less central the novel categories and relations become in an emerging schema.

\section{THE DECONSTRUCTION PROCESS}

Although assimilation may be the starting point of schema emergence, it presents a challenge and tension for ongoing schema development. Although the machine analogy facilitated familiarity with the existing schema, for a new schema to emerge it needs to be seen as conceptually distinct. So, how does this differentiation happen? One possibility would be the gradual development and extension of an existing schema. If this were the case in our study, we would expect to see persistence of the core machine-related categories and relations, identified in Table 1, along with the gradual addition of new categories and relations.

\footnotetext{
${ }^{5}$ Association with broader cultural themes alone does not explain the adoption of the machine analogy. The brain analogy was also associated with a broader cultural movement-cybernetics. Rather, it appears that significant insurance-level effects edited these broader movements.
}

In contrast, our data suggest a different pattern. Assimilation of the schema of computer as machine dominated for the first few years. But its focal categories and relations began to fade by the mid 1960s. Interestingly, the shelved, less prevalent brain-related categories and relations of the late 1950s resurfaced and developed markedly over time. Collectively, a new schema gained strength as the influence of the rejuvenated brain analogy overtook the original machine analogy. We call this process "deconstruction" to highlight the simultaneous breakdown of existing categories and relations and the creation of new ones.

Deconstruction emerged as we tracked changes in the types of categories and relations within the schema. Figure 1 compares the frequency over time of the categories for the initial schema, dominated by the machine analogy, with the final schema, in which the brain-related analogy played a greater role. Figure 2 makes the same comparison at the relational level. Figure 1 shows the initial machinerelated categories persisted into the 1960 s but then began to fade in frequency throughout the 1960s and into the 1970s (see Appendix A for more detail on the categories that faded). Likewise, Figure 2 shows that machine-related relations also began to fade in frequency over the same period of time (see Appendix B for more detail). In contrast, the brainrelated categories and relations in Figures 1 and 2 increased in frequency. One could characterize Figures 1 and 2 as simple replacement, but this does not fully capture the subtle deconstructive changes occurring within the schemas during this time period.

We assess the deconstruction process by precisely identifying changes in categories and relations. To get a better sense of the content of the brain schema, Table 2 shows the most frequent categories and relations prevalent at the end of the observation period and their frequencies in prior periods. Over time, the new categories and relations related to the brain analogy became more specific. From a category perspective, more detailed categories that specifically identified brainlike characteristics, such as "memory," "program," or "instruction," replaced the initial, more general brain category. Whereas earlier, documents in our data set referred to "the computer" as a "brain" that "think[s]" and "reason[s]," the relational structure further developed to more concretely express how the new computer technology aided decision making. Our data referred to how "the computer" and "systems" would "produce" and "prepare" "report[s]" and "information" for "management" and other "users." Thus, the conception of computers shifted; they were no longer machines that pro- 
FIGURE 1

Frequency of Categories over Time (1947-75) ${ }^{\mathrm{a}}$

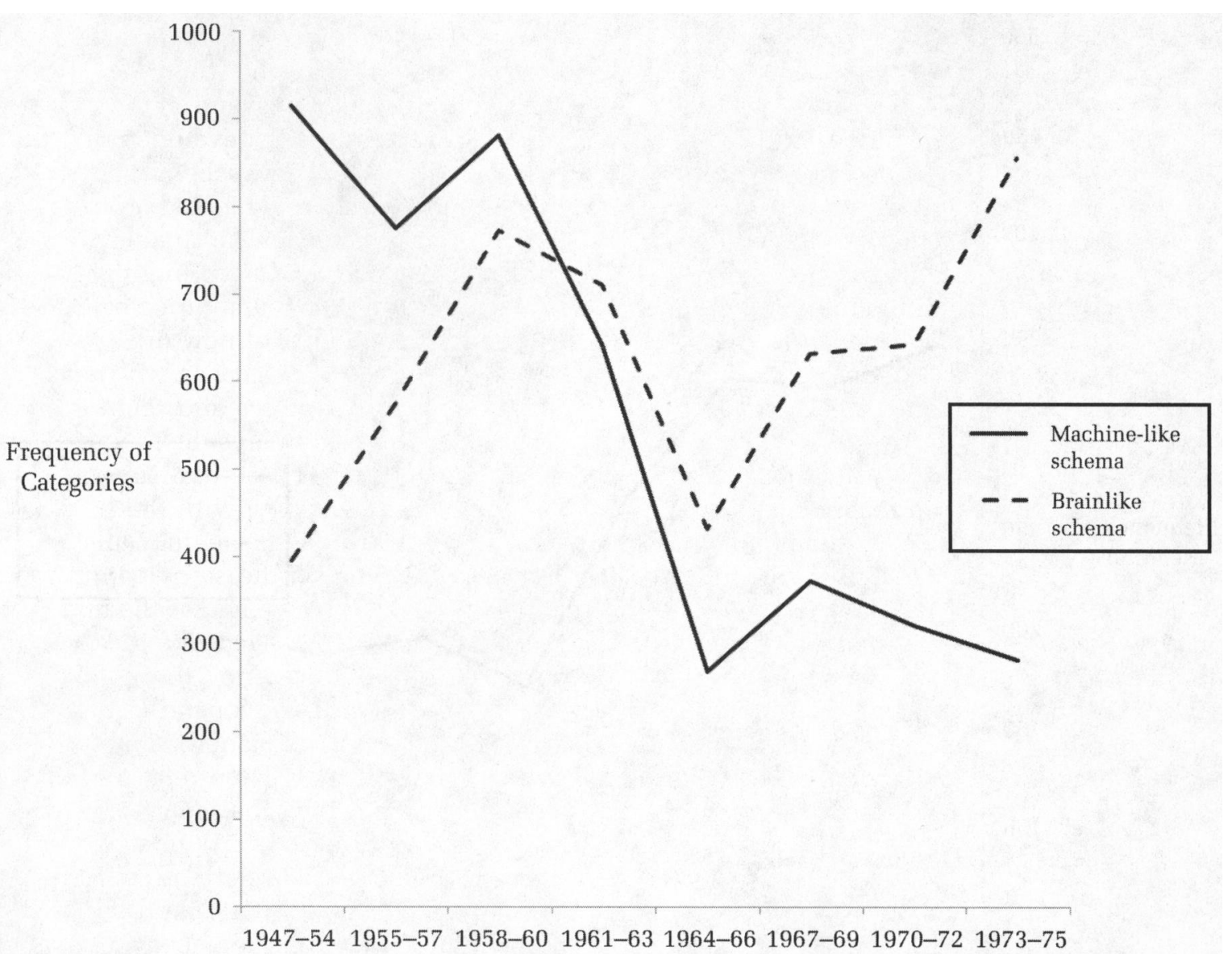

a To calculate the frequencies for the machine-like schema, we identified all categories within the schema during the initial period, 1947-54, and calculated their frequency for each time period. For the brainlike schema, we identified all categories within the schema during the ending period, 1973-75 (see Table 2 for a detail of the more frequent categories), and calculated their frequency for each time period.

duced an output, such as punch cards, for processing transactions-they were "brains" that produced and managed information for decision making.

While the decision-making aspects became more specified, the categories and relations related to the machine analogy became more general. Initially, the texts stressing computers as machines detailed the processes of clerks and operators interacting with machines to process punch cards. This categorical and relational detail helps explain the initial high frequency of terms such as "clerk," "punch," and "punch card," as seen in Table 1. Appendixes A and B show that such terms decreased over time as insurance firms began to replace specific terms with broader concepts that captured the general process. For example, the individual activities of punch card operations were replaced with the single, more generic term "punch card system" (which had 1 occurrence in the first period and increased to 12 occurrences over the next 15 years after the introduction of the computer). Similarly, the detailed specification of clerical work was replaced by more general descriptions, such as "clerical operation" or "clerical work."

Why did this shift happen in the 1960s and not during the initial commercialization of computers in the 1950s? Figures 1 and 2 indicate the deconstruction process was not temporally abrupt, but developed throughout the 1960s, with a sharp increase in brainlike terms by mid decade. Coinciding with this increase, reports began to surface of management complaints about the ineffectiveness of computer use. One of the most cited was McKinsey's report attributing poor returns on early computing investments to their use as "super accounting machines." Criticism of this kind provided negative connotations of machine-like uses and further encouraged the desire for more brainlike functions. 
FIGURE 2

Frequency of Relations over Time $(1947-75)^{\mathrm{a}}$

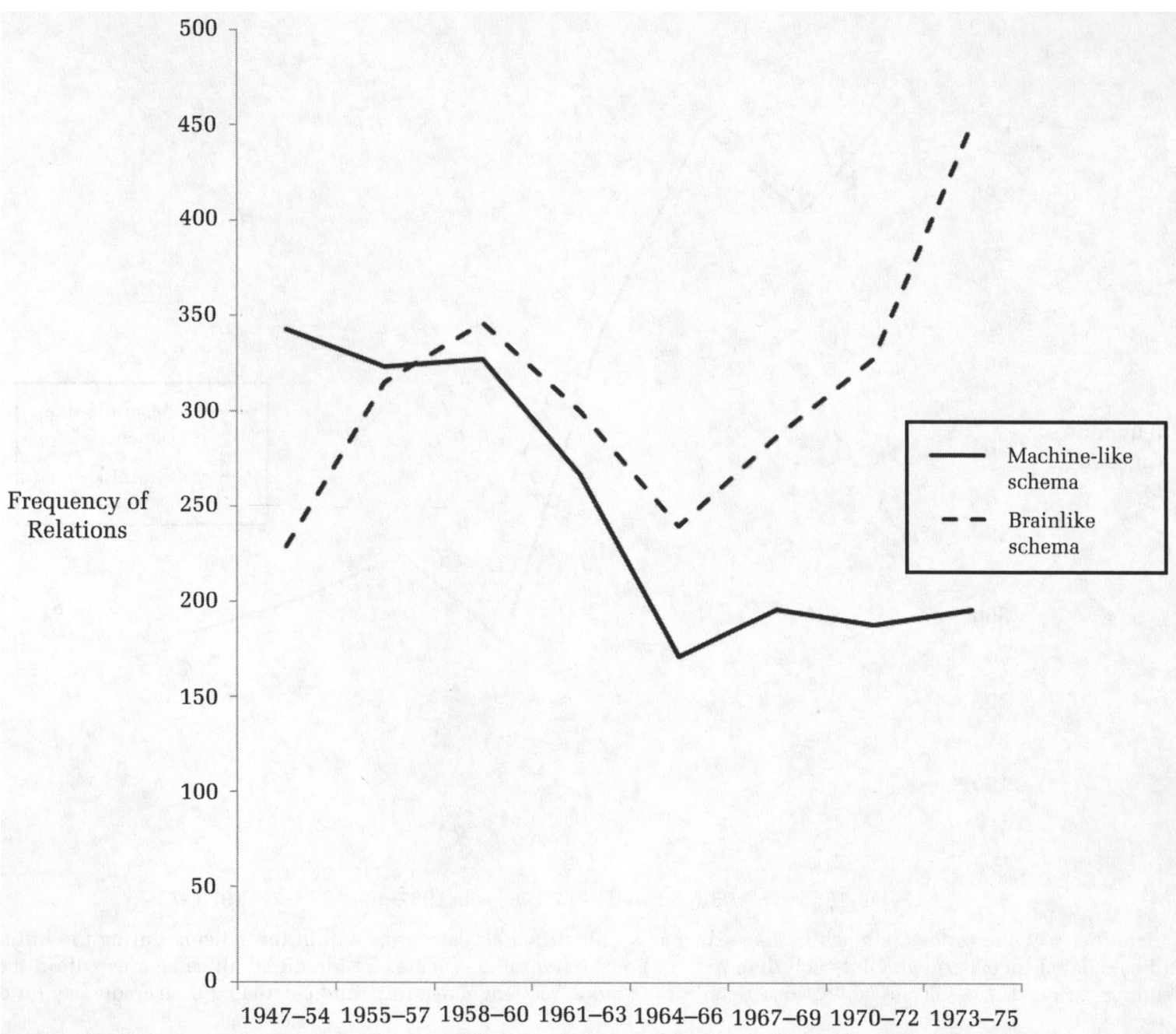

a To calculate the frequencies for the machine-like schema, we identified all the relations within the schema during the initial period,
1947-54, and calculated their frequency for each time period. For the brainlike schema, we identified all the relations within the schema
during the ending period, 1973-75 (see Table 2 for a detail of the more frequent relations), and calculated their frequency for each time
period.

From the technical perspective, computers evolved in ways to better support decision-making processes: solid state computers with disk drives increased data storage and enabled random access of data (Ceruzzi, 1998), processing power increased to support more real-time processing, and terminals improved access (Chandler, 1997). The rise of categories such as "database" and "terminal," shown in Table 2, reflected the commercial introduction of these kinds of technology. At this time, unlike in the late 1940s, insurance firms associated these technological advancements with using computers to make more effective decisions by connecting these new categories through relations such as "store," "update," and "verify." These observations are consistent with Kaplan and Tripsas's (2008) prediction about the interplay between cognitive structures and technology development.

The life insurance industry also learned through their extended use of computers. One key area of learning was programming, as shown by the substantial increase in the categories "program" and "programmer" in Table 2. Originally, insurance firms did not pay much attention to programming. In fact, the SOA report defined programming simply through a comparison with the physical process of wiring tabulating machines together (Davis et al., 1952). However, they discovered programming was significantly more useful than anticipated, which further deconstructed the current schema by introducing new categories and relations. To illustrate, consider this description of pro- 
TABLE 2

History of Brainlike Categories and Relations

\begin{tabular}{|c|c|c|c|c|c|c|c|c|c|}
\hline Schematic Element & $1947-54$ & 1955-57 & $1958-60$ & $1961-63$ & $1964-66$ & $1967-69$ & 1970-72 & 1973-75 & Total \\
\hline \multicolumn{10}{|l|}{ Category } \\
\hline Computer & 15 & 11 & 28 & 32 & 23 & 31 & 28 & 25 & 193 \\
\hline System & 9 & 15 & 25 & 25 & 17 & 19 & 27 & 23 & 160 \\
\hline Information & 21 & 22 & 31 & 34 & 12 & 20 & 17 & 15 & 172 \\
\hline User & 0 & 0 & $\mathbf{0}$ & 0 & 0 & 1 & 3 & 14 & 18 \\
\hline Program & 5 & 23 & 33 & 24 & 19 & 18 & 13 & 13 & 148 \\
\hline Programmer & 5 & 7 & 13 & 8 & 3 & 15 & 6 & 13 & 70 \\
\hline Data & 12 & 16 & 13 & 21 & 9 & 12 & 15 & 11 & 109 \\
\hline Management & 4 & 5 & 13 & 3 & 6 & 14 & 11 & 11 & 67 \\
\hline Terminal & 0 & 0 & $\mathbf{0}$ & 0 & 0 & 3 & 9 & 11 & 23 \\
\hline Software & 0 & 0 & $\mathbf{0}$ & 0 & 0 & 3 & 4 & 11 & 18 \\
\hline Transaction & 1 & 6 & 15 & 16 & 12 & 8 & 9 & 8 & 75 \\
\hline Data processing & 1 & 2 & 7 & 4 & 0 & 6 & 6 & 8 & 34 \\
\hline Data base & 0 & 0 & 0 & 0 & 0 & 3 & 7 & 8 & 18 \\
\hline EDP & 0 & 1 & 11 & 6 & 12 & 9 & 5 & 7 & 51 \\
\hline Computer system & 0 & 2 & 5 & 5 & 8 & 9 & 6 & 7 & 42 \\
\hline Control & 3 & 1 & 2 & 15 & 3 & 3 & 3 & 7 & 37 \\
\hline \multicolumn{10}{|l|}{ Relation } \\
\hline Provide & 0 & 1 & 0 & 1 & 2 & 9 & 8 & 13 & 34 \\
\hline Determine & 5 & 1 & 5 & 4 & 1 & 1 & 6 & 11 & 34 \\
\hline Update & 0 & 3 & 13 & 10 & 7 & 7 & 9 & 10 & 59 \\
\hline Prepare & 4 & 14 & 13 & 14 & 8 & 8 & 12 & 9 & 82 \\
\hline Process & 3 & 9 & 10 & 7 & 7 & 5 & 9 & 9 & 59 \\
\hline Check & 10 & 23 & 18 & 13 & 4 & 7 & 9 & 8 & 92 \\
\hline Produce & 6 & 8 & 14 & 15 & 9 & 7 & 16 & 8 & 83 \\
\hline Generate & 0 & 0 & 0 & 2 & 4 & 3 & 11 & 8 & 28 \\
\hline Review & 0 & 1 & 0 & 0 & 2 & 4 & 3 & 7 & 17 \\
\hline Complete & 0 & 1 & 0 & 0 & 1 & 2 & 1 & 7 & 12 \\
\hline Calculate & 7 & 17 & 18 & 10 & 7 & 3 & 10 & 6 & 78 \\
\hline Handle & 14 & 10 & 6 & 7 & 4 & 3 & 6 & 6 & 56 \\
\hline Store & 9 & 5 & 9 & 8 & 6 & 8 & 3 & 6 & 54 \\
\hline Verify & 3 & 5 & 6 & 4 & 4 & 6 & 2 & 6 & 36 \\
\hline Enter & 3 & 4 & 2 & 6 & 4 & 2 & 8 & 6 & 35 \\
\hline Run & 0 & 8 & 8 & 4 & 2 & 9 & 6 & 6 & 43 \\
\hline Develop & 0 & 2 & 2 & 3 & 6 & 8 & 7 & 6 & 34 \\
\hline Control & 3 & 0 & 3 & 4 & 4 & 4 & 8 & 6 & 32 \\
\hline Make & 1 & 1 & 1 & 3 & 5 & 1 & 3 & 6 & 21 \\
\hline Operate & 4 & 2 & 2 & 2 & 0 & 0 & 1 & 6 & 17 \\
\hline Identify & 0 & 0 & 0 & 0 & 1 & 2 & 1 & 6 & 10 \\
\hline Total articles & 26 & 36 & 60 & 54 & 38 & 50 & 49 & 45 & 358 \\
\hline
\end{tabular}

gramming, from a member of the insurance firm State Farm: "Electronic Data Processing equipment is a tool and not an electronic brain, or any other kind of brain.... It is nothing more than a superspeed 'moron' acting on detailed instructions. The programmers who direct its operations are the real 'brains'” (Marquardt, 1960: 255). Marquardt did not completely abandon the classification of a computer as a piece of equipment but cast doubt on the machine analogy. Computers followed "detailed instructions"; machines functioned mechanically. Moreover, Marquardt recognized a new kind of user, programmers, who interfaced with computers differently than did the clerks who operated them.
To summarize, although the machine analogy with its transaction-oriented categories and relations still persisted, it became noticeably weaker as insurance firms expanded their understanding of the new technology. The conceptual focus of the schema actually expanded to include categories and relations from both the machine and brain analogies, until categories and relations related to the machine analogy became less frequent and categories and relations related to the brain analogy became more frequent.

A key question is why deconstruction facilitates schema emergence. One reason is it separates a new schema from an existing schema. Here, the desta- 
bilization of the previously strong conceptual boundaries between categories and relations in the existing schema shifted to previously ignored categories (e.g., information) and relations (e.g., programming, decision making, and thinking) related to the brain analogy. In general, this finding implies a more dynamic and process-oriented view of analogies than that in the existing literature by highlighting the interplay of multiple analogies over time. Our findings show multiple analogies not only exist, but also persist. The brain analogy did not disappear when the machine analogy became more dominant. Rather, it remained stationary but embedded in memory. It was rereleased through the use of computers and as the conceptual mapping of computer to brain was more frequently and cogently articulated. This is consistent with research noting that if features of something novel (i.e., "computer") can be considered at a more abstract level (e.g., "thinking" or "decision making" of computer), then what is novel (i.e., computer) has the potential to be related to what on the surface level might appear to be an unfit analog (e.g., brain) (Chi, Feltovich, \& Glaser, 1981).

Besides suggesting that deconstruction happens, our study also reveals insight into the logic of how deconstruction happens. Although the logic of our first finding, assimilation, relates to the familiar/ novel nature of analogies, we find that the logic of our second finding, deconstruction, relates to the general/specific nature of analogies. In our data, making categories and relations more general appeared to weaken the power of the machine analogy since the removal of specific terms left only a few general terms of "machine," resulting in less fervor surrounding machine-like qualities. Making categories and relations more specific alternatively appeared to have the effect of strengthening the brain analogy because the addition of more precise terms added new discrete linkages to the analogy strengthening its relevance. Taken together, these observations lead to our next proposition:

Proposition 2. Categories and relations are more likely to become deconstructed when they become more general and less specific.

\section{THE UNITIZATION PROCESS}

Although deconstruction boosted the invocation of novel categories and relations associated with the brain analogy, it did not establish them as a new schema. Creation alone does not complete emergence until it is proven to persist. In our data, we observe that the categories and relations borne of the deconstruction process in the 1960s established themselves as a new schema through unitization in the 1970s. Like Hayes-Roth (1977), we define unitization as the process through which a group of categories and relations get connected in such a way that they are used as a stand-alone unit and no longer exist solely as individual components.

One way to measure unitization is by the concentration of certain groupings of categories and relations-the greater the concentration of certain groupings, the higher the level of unitization. This is evident in Table 2, which shows an increasing concentration in categories and relations associated with information processing to make management decisions. This includes such categories as "system," "information," "management," "program," and relations such as "provide," "determine," and "update." In addition to high concentrations, closely interconnected terms suggest they function more strongly as a unit than individually. To assess connectedness, we took a representative category of the machine-related schema, "machine," and a representative category of the brain-related schema, "system," and counted the frequencies of the different categories they each were connected with (through relations) for each time period. Table 3 shows these results, indicating that "machine" was initially well connected with other categories but over time became less so. By contrast, "system" became increasingly connected over time. Moreover, "system" became tightly affiliated with a broad array of categories, many associated with decision making, such as "evaluation team," "calculation," and even "decision making" itself.

The increasing connectedness indicates a unit structure emerged around the categories and relations associated with decision making, distinct from the schema originally assimilated in the

TABLE 3

The Connectivity of "Machine" and "System"

\begin{tabular}{|c|c|c|c|c|c|c|c|c|}
\hline Representative Category & 1947-54 & 1955-57 & $1958-60$ & 1961-63 & $1964-66$ & $1967-69$ & $1970-72$ & 1973-75 \\
\hline Machine connectivity & 209 & 36 & 14 & 8 & 0 & 4 & 3 & 2 \\
\hline Machine articles & 20 & 21 & 28 & 9 & 4 & 5 & 4 & 4 \\
\hline System connectivity & 1 & 2 & $\mathbf{0}$ & 10 & 28 & 11 & 64 & 54 \\
\hline System articles & 9 & 15 & 25 & 25 & 17 & 19 & 27 & 23 \\
\hline
\end{tabular}


1950s. This process had the effect of simplifying the broader conceptual space exhibited during deconstruction around fewer categories and relations linking to the brain analogy. This may seem counterintuitive. After all, the deconstructed schema was broad, with categories and relations that stressed the relevance of both machine and brain analogies. To illustrate this transition, reconsider the introduction of database technology into the schema. In 1975, Robert Shafto of New England Mutual Life Insurance described a database as "that set of data-fields related to the 'complete' performance of all required transactions regardless of how those data-fields are organized . . . but to truly complete the performance, it must also include those needed to provide 'management information'” (Shafto, 1975: 251).

This new vision of data residing in its own "base," which was emphasized by the original form of the term "data base," represented a shift in thinking about data as independent rather than tied to a specific transaction that they supported. Data freed from transactions could now be used for a variety of purposes, including processing "management information." Indeed, Table 2 indicates this trend in thought by showing the noticeable increased use of the terms "data base" and "store."

Related to the growth of database technology, the MIS movement of the early 1970s also facilitated the unitization process. Howard Arner of American Bankers Life defined a MIS as "the orderly combination of facts for management" (Arner, 1972: 15). The use of a MIS was intended to leverage computers as a means of processing information that supported managerial decisions. The historian Haigh (2001) noted that at a broad level, the MIS movement was closely tied to the systems workers' desire to expand their jurisdictional control in organizations. Systems employees were responsible for business process design and forms control, and they authored many of the computer articles published in association proceedings and received significant attention in the insurance industry, such as the granting of individual sessions at the IASA proceedings in the early 1970 s. Although MIS had limited success in terms of actually being implemented (Haigh, 2001), it had a profound impact on unitizing the emerging computer schema within the insurance industry by perpetuating the connectedness of the developing categories of information and manager/information user in decisionmaking relations.

An important question is why the process of unitization relates to schema emergence. Unitization helps separate new categories and relations from those in existing schemas and establishes them as a holistic cognitive unit. Studies in human perception find that ongoing experience with specific configurations of cognitive components and relations can result in the formation of a single image-like representation (Goldstone, 2000). In line with this view, from the late 1960s into the early 1970 s, insurance firms began to invoke a consistent image of computers that integrated the novel categories (e.g., programmer, manager, information) and relations (e.g., decide, prepare, service) related to the original brain analogy. Our data show strong support for statements of brain-related categories connected to other categories through decisionmaking relations.

In contrast, there is an accelerated disconnection between categories related to machines. This suggests the process of unitization follows a pattern of connectedness. Statements from users encompassed a few "core" brain-related categories and relations used together. This core became associated with a conceptually distinct unit of knowledge, and thus a new schema began to form. As a consequence, the machine analogy was slowly forced to the periphery as it began to have less significant meaning. This push to the periphery enabled the new schema to gain momentum as the conceptual differences between it and the preexisting schema became clearer. These observations lead to our final proposition:

Proposition 3. The more connected a group of
categories and relations become, the stronger
they emerge as a stand-alone cognitive unit.

\section{DISCUSSION}

Schemas are a central concept in the strategy and organizations literatures. They help establish industry boundaries, foster relational capital, and fortify competitive positioning. This study addresses the emergence of collective schemas. Using 30 years of in-depth qualitative and quantitative data, we explore how groups in the insurance industry developed a collective schema for what came to be known as "the computer."

\section{Schema Emergence Process}

A primary contribution is an emergent theoretical framework for how a collective schema emerges over time. First, schema emergence starts with assimilation. We find that although firms face multiple analogies to help them understand new technologies, they select the analogy that is most similar to prior technological solutions. However, 
although prior literature suggests that assimilation can be positive by legitimating what is new (Hargadon \& Douglas, 2001), we find that similar analogies can have negative consequences for schema development because they make an existing schema the conceptual focus, not the new categories and relations. Consequently, although assimilation of a new schema into an existing schema helps make the unfamiliar familiar, it can negatively impact the development of the new schema because the more novel aspects of a technology (here, for example, programming and decision making) get pushed to the periphery.

Second, a new schema further develops through deconstruction of existing schemas. Schemas are meant to provide simplified representations of the world that enable more efficient processing of complex information (Fiske \& Taylor, 1984). They are not useful if they do not accurately represent the world or filter out too much information. That is, a schema must be valid to a certain degree. However, most research that invokes schemas does not directly address their validity (Walsh, 1995). Our study reveals how early use of computers served as a means of validating an initial schema. Over time, insurance firms began to better understand the uses of computer technology. This, in turn, lowered the descriptive power of the initial machine analogy, as evidenced by the decreasing frequency and increasing generalization of the categories and relations supporting it. Simultaneously, it strengthened the previously unrealized brain analogy, as evidenced by the increasing frequency and specificity of the categories and relations supporting it. The overall effect of deconstruction, then, is a broadening of the categories and relations in the conceptual focus of users. Yet, though it is an important process of schema emergence, deconstruction still does not result in a new, stand-alone schema, because the categories and relations within the conceptual focus still maintain ties to the preexisting schema.

A final process of schema development is unitization. As technological advancements and use of computers increased over time, the machine analogy weakened; categories related to the machine analogy were less frequently used and became less connected with one another. By contrast, the categories related to the brain analogy were more frequently used and formed stronger connections with each other. As a result, categories and relations associated with the original brain analogy came to constitute a distinct and single unit in memory, one that had almost no ties to categories and relations of other schemas and was thus theoretically equivalent to a novel schema (in this case, a schema for "the computer"). Therefore, a key point is that a new schema may not emerge as a stand-alone cognitive unit until late in its developmental process. Indeed, almost 20 years had passed since the commercial release of computers before categories and relations comprising the emergent computer schema were invoked in an all or none fashion.

\section{Implications for Managerial Cognition}

Broadly, our study contributes to the managerial cognition literature by setting forth a pluralistic view of analogies. Much research on analogical transfer forwards the argument that, facing a new situation, individuals think back to some previous situation they know about and apply the lessons from the previous situation to the new one (Gavetti et al., 2005; Gick \& Holyoak, 1983). This body of research grants that individuals may have different analogies but contains little discussion about how different analogies might be reconciled, because its assumption is that individuals process their own analogies sequentially and focus on one that fits a new situation best.

In contrast, we highlight a pluralistic view. A counterintuitive insight is that the use of multiple analogies from different sources may be both more efficient and effective for schema development than the use of single analogies. One reason is that the value of one analogy can be difficult to assess in isolation. Studies on collective decision making have shown that having more than one alternative helps executives determine each alternative's benefits and detriments (e.g., Eisenhardt, 1989; Schweiger, Sandberg, \& Rechner, 1989). Thus, multiple analogies lead to the efficient debate of ideas and a deeper, relational understanding. The use of multiple analogies also reduces commitment to any single one of them. When organizations entertain multiple analogies, they are less likely to become cognitively entrenched in any one analogy and thus can shift to a new analogy (e.g., "brain") if their ongoing experience does not support a particular analogy (e.g., "machine"). Much psychology research on analogies misses these advantages because it puts individuals into controlled environments, where interaction with others is absent and explicit "hints" are provided to identify unambiguous analogs. Organizational research misses these advantages because it largely focuses on the attributes and influence of single analogies (Gavetti et al., 2005). In other words, by omitting exploration of the interplay of multiple analogies over time, research provides a limited and fairly static view of analogical transfer.

By contrast, in firms single analogies may be not only less accurate but also less efficient for schema 
development. For example, psychology studies examining whether subjects can foster the development of a schema from a single story analog find little evidence of success (Gick \& Holyoak, 1983). Likewise, organizational research suggests many analogies are based on superficial features of problems (Gavetti et al., 2005), and because of this, the use of a single analogy may make firms likely to overweight or overgeneralize similarities from one context to another. The more fundamental implication is that pluralism is so readily apparent in organizations yet is often missing from academic theories on managerial cognition (for exceptions, see Kaplan [2008a, 2008b]). Thus, many organizational theorists studying cognition import individuallevel psychological theories without fully adjusting them to reveal the differences at higher, collective levels of analysis, where a diversity of views about work related issues are more the norm than the exception (Bingham \& Haleblian, 2012).

A key contribution of this study, therefore, is complementing the many studies examining the individual origins of collective constructs (e.g., capabilities and competencies) by examining the opposite, but largely overlooked, direction-how individual-level theories (e.g., analogical transfer) might play out differently at a collective level (Bingham \& Eisenhardt, 2011; Bingham \& Haleblian, 2012). Succinctly stated, our study suggests models of analogical transfer from single analogies may allow parsimony, but they are often untrue in the context of organizations and come at the expense of empirical validity.

\section{Implications for Change Theory}

Our study contributes to change theory by emphasizing the management of paradox, the simultaneous existence of two inconsistent states, an increasingly important theme in work on change (Eisenhardt, 2000). In the case of emergence, the two prominent inconsistent states are "familiarity" and "novelty." A delicate tension exists when new schemas are born: the new must be made familiar enough to garner short-term attention, and at the same time, it must remain distinct to avoid longerterm assimilation. Our study shows that rather than manage technical change by splitting familiar (machine) and novel (brain) analogies, the insurance industry was aware of and utilized both.

The industry first appeared to manage technical change by anchoring new ideas to familiar work. Although anchoring new ideas in a familiar context appears useful to start change, our study suggests it may be less useful in sustaining change, where accentuating the novel appears key. In particular, the analogy of computer as machine helped users quickly integrate it into the well-established existing schema. This swift integration of "the computer," however, caused those assimilating the schema to lose sight of computers' most innovative aspects. Consequently, although anchoring new ideas to the familiar provides utility, organizations must overcome the threat of those ideas becoming too deeply assimilated (Rindova \& Petkova, 2007). By contrast, not anchoring new ideas to a familiar context may be more useful to sustain change. Thus, although the novel brain analogy provided limited categories or relations with which to anchor it to the existing schema, it did help distinguish computers from the existing technology so that their unique features could gain attention later.

Our study also shows that one way to manage this tension at the schema level is through the interplay of generalization and specification of the categories and relations that comprise a schema. Initially, the more specific categories and relations of the machine analogy facilitated its assimilation. By contrast, the brain analogy was too general. For example, although Berkeley's (1947) presentations to the three national insurance associations identified a list of potential applications, they included no specific business process diagrams or data requirements and provided very little discussion of the actual application of computers to solve familiar business problems. Rather, they focused on the general ability of computers to "think" the way humans do by isolating the various abstract functions of thinking. As a result, his presentations lacked the level of granularity about computer use that members of the associations were accustomed to, presumably making his ideas harder to understand.

However, during the deconstructive phase, the categories and relations of the highly assimilated machine-related categories and relations became increasingly generalized, which facilitated the differentiation process and helped push them to the periphery. In contrast, the brain-related categories and relations become increasingly specified, which helped build out the structure of the new schema. The concurrent existence of more generalized and specific sets of categories and relations within the broader schema helped manage the dual states of familiarity and novelty found in the emergent process. Overall, the management of change appears to hinge on exploiting the duality between familiar and novel in a way that captures both states, thereby capitalizing on the pluralism inherent in that duality. 


\section{Limitations and Future Research}

Like all research, our research has limitations that suggest opportunities for future research. We identified three distinctive processes-assimilation, deconstruction, and unitization-involved in schema emergence and presented them in sequential order because that is how they unfolded in the insurance case; however, future research is needed to validate this order and consider the conditions under which it may not occur. Our research suggests that assimilation, deconstruction, and unitization each relates to the use of analogies. Yet it may be that in a different setting, analogies have different effects, or different cognitive mechanisms play a role. Finally, our study focuses on an emergent schema associated with a new technology. This raises the question of whether our insights generalize beyond technology settings. We believe that our findings are relevant to other contexts characterized by complexity, unpredictability, and uncertainty-situations in which analogies play an important role. Overall, an important next step is submitting our emergent findings to rigorous empirical validation and extension.

\section{Conclusions}

Our central contribution is an emergent theoretical framework for schema emergence. This framework begins to illuminate how a new schema can be made familiar but distinct from existing schemas through the sharing of categories and relations and the manipulation of their generalization and interconnectedness. Like existing work, our study also suggests that schema emergence is associated with the use of analogies. But, unlike much of this work, our study reveals a more pluralistic, dynamic view of analogies. A key theoretical insight of our work is that although individual-level concepts (e.g., analogies) from psychology are often relevant at higher levels of analysis, they should not simply be applied to those higher levels on a one-to-one basis. Our research adjusts concepts from psychology to account for features that are uniquely organizational (e.g., the presence of multiple analogies). Overall, by exploiting the unique features of indepth historical analysis and considering fundamental organizational features, we find that schema emergence relates to a view of analogies that is more nuanced than the view that exists in the literature-a view that reveals the impact of not only the quantity and qualities of analogies, but also their temporal interchange.

\section{REFERENCES}

Adams, W. J. 1946. A progress report of the association costs committee. LOMA Annual Proceedings: 119127

Arner, H. 1972. What is MIS. Proceedings of the Insurance Accounting and Statistical Association: 1517.

Barr, P. S., Stimpert, J. L., \& Huff, A. S. 1992. Cognitive change, strategic action, and organizational renewal. Strategic Management Journal, 13: 15-36.

Bartunek, J. M. 1984. Changing interpretive schemes and organizational restructuring: The example of a religious order. Administrative Science Quarterly, 29: 355-372.

Bashe, C. J., Johnson, L. R., Palmer, J. H., \& Pugh, E. W. 1986. IBM's early computers. Cambridge, MA: MIT Press.

Beebe, F. 1947. Application of punched card accounting machines. LOMA Annual Proceedings: 190-202.

Benford, R. D., \& Snow, D. A. 2000. Framing processes and social movements: An overview and assessment. In K. Cook \& J. Hagan (Eds.), Annual review of sociology, vol. 26: 611-639. Palo Alto, CA: Annual Reviews.

Benner, M., \& Tripsas, M. 2012. The influence of prior industry affiliation on framing in nascent industries: The Evolution of digital cameras. Strategic Management Journal, 33: 277-302.

Berkeley, E. C. 1949. Giant brains: Or, machines that think. New York: Wiley.

Bingham, C. B., \& Eisenhardt, K. M. 2011. Rational heuristics: The "simple rules" that strategists learn from their process experiences. Strategic Management Journal, 32: 1437-1464

Bingham, C. B., \& Haleblian, J. 2012. How firms learn heuristics: Uncovering missing components of organizational learning. Strategic Entrepreneurship Journal, 6(2): 152-177.

Bureau of Labor Statistics. 1955. The introduction of an electronic computer in a large insurance company, USDO Studies of Automatic Technology, no. 2. Washington, DC: U.S. Government Printing Office.

Carley, K. 1993. Coding choices for textual analysis: A comparison of content analysis and map analysis. Sociological Methodology, 23: 75-126.

Carley, K. 1997. Extracting team mental models through textual analysis. Journal of Organizational Behavior, 18: 533-558.

Ceruzzi, P. 1998. A history of modern computing. Cambridge, MA: MIT Press.

Chandler, A. 1997. The computer industry: The first halfcentury. In D. Yoffie (Ed.), Competing in the age of 
digital convergence: 37-122. Boston: Harvard Business School Press.

Chi, M. T. H., Feltovich, P. J., \& Glaser, R. 1981. Categorization and representation of physics problems by experts and novices. Cognitive Science, 5: 121-152.

Clark, K. B. 1985. The intersection of design hierarchies and market concepts in technological Evolution. Research Policy, 14: 235-251.

Cooley, E. F. 1953. Electronic machines-Their use by life companies. Proceedings of the Life Office Management Association: 355-363.

Dane, E. 2010. Reconsidering the trade-off between expertise and flexibility: A cognitive entrenchment perspective. Academy of Management Review, 35: 579-603.

Davis, M. E., Barber, W. P., Finelli, J. J., \& Klem, W. 1952. Report of committee on new recording means and computing devices. Chicago: Society of Actuaries.

DiMaggio, P. 1997. Culture and cognition. In K. Cook \& J. Hagan (Eds.), Annual review of sociology, vol. 23: 263-287. Palo Alto, CA: Annual Reviews.

Eisenhardt, K. M. 1989. Building theories from case study research. Academy of Management Review, 14: 532-550.

Eisenhardt, K. M. 2000. Paradox, spirals, ambivalence: The new language of change and pluralism. Academy of Management Review, 25: 703-705.

Elsbach, K. D., Barr, P. S., \& Hargadon, A. B. 2005. Identifying situated cognition in organizations. Organization Science, 16: 422-433.

Eden, D., \& Shani, A. B. 1982. Pygmalion goes to boot camp: Expectancy, leadership, and trainee performance. Journal of Applied Psychology, 67: 194-199.

Etzion, D., \& Ferraro, F. 2010. The role of analogy in the institutionalization of sustainability reporting. $\mathrm{Or}$ ganization Science, 21: 1092-1107.

Fiske, S. T., \& Dyer, L. M. 1985. Structure and development of social schemata: Evidence from positive and negative transfer effects. Journal of Personality and Social Psychology, 48: 839-852.

Fiske, S. T., \& Taylor, S. E. 1984. Social cognition. Reading, MA: Addison-Wesley.

Gavetti, G., Levinthal, D. A., \& Rivkin, J. W. 2005. Strategy making in novel and complex worlds: The power of analogy. Strategic Management Journal, 26: 691-712.

Gentner, D. 1983. Structure-mapping: A theoretical framework for analogy. Cognitive Science, 7: 155-170.

Gentner, D., \& Markman, A. 1997. Structure mapping in analogy and similarity. American Psychologist, 52: 45-56.
Gick, M. L., \& Holyoak, K. J. 1983. Schema induction and analogical transfer. Cognitive Psychology, 15: 1-38.

Goffman, E. 1974. Frame analysis. Cambridge, MA: Harvard University.

Goldstone, R. L. 2000. Unitization during category learning. Journal of Experimental Psychology. Human Perception and Performance, 26: 86-112.

Haigh, T. 2001. Inventing information systems: The systems men and the computer, 1950-1968. Business History Review, 75: 15-61.

Hannan, M., Polos, L., \& Carroll, G. 2007. Logics of organization theory: Audiences, codes, and ecologies. Princeton, NJ: Princeton University Press.

Hargadon, A., \& Sutton, R. I. 1997. Technology brokering and innovation in a product development firm. Administrative Science Quarterly, 42: 716-749.

Hargadon, A., \& Douglas, Y. 2001. When innovations meet institutions: Edison and the design of the Electric light. Administrative Science Quarterly, 46: 476-501.

Hargadon, A., \& Fanelli, A. 2002. Action and possibility: Reconciling dual perspectives of knowledge in organizations. Organization Science, 13: 290-302.

Hayes-Roth, B. 1977. Evolution of cognitive structures and processes. Psychological Review, 84: 260-278.

Holyoak, K. J., \& Thagard, P. 1989. Analogical mapping by constraint satisfaction. Cognitive Science, 13: 295-355.

Kaplan, S. 2008a. Cognition, capabilities, and incentives: Assessing firm response to the fiber-optic revolution. Academy of Management Journal, 51: 672-695.

Kaplan, S. 2008b. Framing contests: Strategy making under uncertainty. Organization Science, 19: 729752.

Kaplan, S., \& Tripsas, M. 2008. Thinking about technology: Applying a cognitive lens to technical change. Research Policy, 37: 790-805.

Lee, T. W. 1999. Using qualitative methods in organizational research. Thousand Oaks, CA: Sage.

Loewenstein, J., \& Gentner, D. 2005. Relational language and the development of relational mapping. Cognitive Psychology, 50: 315-353.

Marquardt, C. A. 1960. Maintaining programs, making changes, etc.-Periodic audits to determine accuracy of performance and adherence to prescribed routines processed by the computer. Proceedings of the Insurance Accounting and Statistical Association: 255-256.

Misangyi, V. F., Weaver, G. R., \& Elms, H. 2008. Ending corruption: The interplay among institutional logics, resources, and institutional Entrepreneurs. Academy of Management Review, 33: 750-770. 
Nadkarni, S., \& Narayanan, V. K. 2007. Strategic schemas, strategic flexibility, and firm performance: The moderating role of industry clockspeed. Strategic Management Journal, 28: 243-270.

Novick, L. R., \& Holyoak, K. J. 1991. Mathematical problem solving by analogy. Journal of Experimental Psychology. Learning, Memory, and Cognition, 17: $398-415$.

Rindova, V., \& Petkova, A. 2007. When is a new thing a good thing? Technological change, product form design, and perceptions of value for product innovations. Organization Science, 18: 217-232.

Schminke, M., Ambrose, M., \& Noel, T. 1997. The effects of ethical frameworks on perceptions of organizational justice. Academy of Management Journal, 40: $1190-1207$.

Schon, D. 1993. Generative metaphor: A perspective on problem-setting in social policy. In A. Ortony (Ed.), Metaphor and thought: 137-163. New York: Cambridge University Press.

Schustack, M. W., \& Anderson, J. R. 1979. Effects of analogy to prior knowledge on memory for new information. Journal of Verbal Learning and Verbal Behavior, 18: 565-583.

Schweiger, D. M., Sandberg, W. R., \& Rechner, P. L. 1989. Experiential effects of dialectical inquiry, devil's advocacy, and consensus approaches to strategic decision making. Academy of Management Journal, 32: 745-772.
Shafto, R. A. 1973. Building the data base. Proceedings of the Insurance Accounting and Statistical Association: $250-253$.

Tripsas, M., \& Gavetti, G. 2000. Capabilities, cognition and inertia: Evidence from digital imaging. Strategic Management Journal, 21: 1147-1162.

Tsoukas, H. 2009. A dialogical approach to the creation of new knowledge in organizations. Organization Science, 20: 941-957.

Walsh, J. P. 1995. Managerial and organizational cognition: Notes from a trip down memory lane. Organization Science, 6: 280-321.

Weick, K. E. 1979. Cognitive processes in organizations. In B. Staw (Ed.), Research in organizational behavior, vol. 1: 41-74. Greenwich, CT: JAI.

Winston, P. H. 1980. Learning and reasoning by analogy. Communications of the ACM, 23: 689-703.

Yates, J. 1989. Control through communication: The rise of system in American management. Baltimore: Johns Hopkins University Press.

Yates, J. 1997. Early interactions between the life insurance and computing industries: The Prudential's Edmund C. Berkeley. Annals of the History of Computing, 19(3): 60-73.

Yates, J. 2005. Structuring the information age: Life insurance and technology in the 20th century. Baltimore: John Hopkins University Press. 
APPENDIX A

Most Frequent Categories over Time

\begin{tabular}{|c|c|c|c|c|c|c|c|c|c|}
\hline Category & 1947-54 & 1955-57 & $1958-60$ & $1961-63$ & $1964-66$ & 1967-69 & $1970-72$ & 1973-75 & Total \\
\hline Computer & 15 & 11 & 28 & 32 & 23 & 31 & 28 & 25 & 193 \\
\hline Information & 21 & 22 & 31 & 34 & 12 & 20 & 17 & 15 & 172 \\
\hline System & 9 & 15 & 25 & 25 & 17 & 19 & 27 & 23 & 160 \\
\hline Program & 5 & 23 & 33 & 24 & 19 & 18 & 13 & 13 & 148 \\
\hline Punch card & 14 & 31 & 37 & 24 & 5 & 7 & 5 & 5 & 128 \\
\hline Data & 12 & 16 & 13 & 21 & 9 & 12 & 15 & 11 & 109 \\
\hline Card & 12 & 28 & 24 & 17 & 7 & 8 & 5 & 2 & 103 \\
\hline Machine & 20 & 21 & 28 & 9 & 4 & 5 & 4 & 4 & 95 \\
\hline Programming & 10 & 16 & 23 & 14 & 7 & 8 & 7 & 5 & 90 \\
\hline File & 11 & 20 & 20 & 17 & 6 & 4 & 1 & 5 & 84 \\
\hline Transaction & 1 & 6 & 15 & 16 & 12 & 8 & 9 & 8 & 75 \\
\hline Programmer & 5 & 7 & 13 & 8 & 3 & 15 & 6 & 13 & 70 \\
\hline Clerk & 12 & 13 & 22 & 11 & 1 & 2 & 5 & 4 & 70 \\
\hline Policy & 8 & 17 & 16 & 10 & 7 & 6 & 4 & 2 & 70 \\
\hline Tape & 12 & 9 & 16 & 14 & 6 & 6 & 4 & 1 & 68 \\
\hline Management & 4 & 5 & 13 & 3 & 6 & 14 & 11 & 11 & 67 \\
\hline Record & 11 & 8 & 15 & 11 & 6 & 7 & 5 & 4 & 67 \\
\hline Home office & 7 & 10 & 16 & 4 & 7 & 9 & 10 & 3 & 66 \\
\hline IBM 1401 & 0 & 0 & 2 & 20 & 11 & 18 & 7 & 6 & 64 \\
\hline IBM 650 & 4 & 24 & 23 & 4 & 0 & 3 & 1 & 1 & 60 \\
\hline Equipment & 13 & 12 & 13 & 6 & 1 & 3 & 2 & 5 & 55 \\
\hline Magnetic tape & 10 & 15 & 9 & 8 & 3 & 3 & 4 & 2 & 54 \\
\hline EDP & 0 & 1 & 11 & 6 & 12 & 9 & 5 & 7 & 51 \\
\hline Operation & 10 & 11 & 11 & 11 & 1 & 3 & 0 & 4 & 51 \\
\hline Application & 2 & 11 & 13 & 8 & 2 & 1 & 4 & 6 & 47 \\
\hline Commission & 3 & 15 & 15 & 7 & 2 & 1 & 1 & 3 & 47 \\
\hline Job & 6 & 14 & 13 & 6 & 3 & 4 & 0 & 1 & 47 \\
\hline Routine & 8 & 9 & 7 & 8 & 3 & 7 & 2 & 1 & 45 \\
\hline Conversion & 0 & 1 & 13 & 19 & 5 & 3 & 0 & 3 & 44 \\
\hline Computer system & 0 & 2 & 5 & 5 & 8 & 9 & 6 & 7 & 42 \\
\hline Report & 3 & 6 & 8 & 5 & 5 & 9 & 2 & 4 & 42 \\
\hline Master file & 2 & 6 & 6 & 12 & 5 & 4 & 2 & 4 & 41 \\
\hline Agent & 3 & 3 & 2 & 3 & 7 & 8 & 11 & 2 & 39 \\
\hline Policyholder & 8 & 7 & 11 & 4 & 2 & 5 & 2 & 0 & 39 \\
\hline Control & 3 & 1 & 2 & 15 & 3 & 3 & 3 & 7 & 37 \\
\hline Total articles & 26 & 36 & 60 & 54 & 38 & 50 & 49 & 45 & 358 \\
\hline
\end{tabular}

${ }^{a}$ Each cell represents the total number of articles that used the particular category during the time period. To be included in the table, the category was required to appear in approximately 10 percent of the total articles from 1947 through 1975. 
APPENDIX B

Most Frequent Relations over Time ${ }^{\mathrm{a}}$

\begin{tabular}{|c|c|c|c|c|c|c|c|c|c|}
\hline Relation & $1947-54$ & 1955-57 & $1958-60$ & $1961-63$ & $1964-66$ & $1967-69$ & $1970-72$ & 1973-75 & Total \\
\hline Check & 10 & 23 & 18 & 13 & 4 & 7 & 9 & 8 & 92 \\
\hline Punch & 2 & 20 & 23 & 16 & 7 & 11 & 6 & 1 & 86 \\
\hline Produce & 6 & 8 & 14 & 15 & 9 & 7 & 16 & 8 & 83 \\
\hline Prepare & 4 & 14 & 13 & 14 & 8 & 8 & 12 & 9 & 82 \\
\hline Calculate & 7 & 17 & 18 & 10 & 7 & 3 & 10 & 6 & 78 \\
\hline Write & 8 & 9 & 14 & 7 & 6 & 13 & 4 & 4 & 65 \\
\hline Process & 3 & 9 & 10 & 7 & 7 & 5 & 9 & 9 & 59 \\
\hline Update & 0 & 3 & 13 & 10 & 7 & 7 & 9 & 10 & 59 \\
\hline Sort & 9 & 11 & 8 & 11 & 5 & 5 & 7 & 2 & 58 \\
\hline Convert & 3 & 11 & 14 & 13 & 5 & 4 & 5 & 3 & 58 \\
\hline Handle & 14 & 10 & 6 & 7 & 4 & 3 & 6 & 6 & 56 \\
\hline Store & 9 & 5 & 9 & 8 & 6 & 8 & 3 & 6 & 54 \\
\hline Print & 8 & 3 & 9 & 10 & 8 & 7 & 5 & 2 & 52 \\
\hline Run & 0 & 8 & 8 & 4 & 2 & 9 & 6 & 6 & 43 \\
\hline Merge & 4 & 13 & 9 & 7 & 2 & 3 & 1 & 2 & 41 \\
\hline Program & 4 & 8 & 11 & 5 & 2 & 4 & 2 & 5 & 41 \\
\hline Verify & 3 & 5 & 6 & 4 & 4 & 6 & 2 & 6 & 36 \\
\hline Read & 13 & 7 & 2 & 2 & 4 & 4 & 1 & 3 & 36 \\
\hline Enter & 3 & 4 & 2 & 6 & 4 & 2 & 8 & 6 & 35 \\
\hline Develop & 0 & 2 & 2 & 3 & 6 & 8 & 7 & 6 & 34 \\
\hline Pass through & 1 & 8 & 13 & 5 & 2 & 1 & 2 & 2 & 34 \\
\hline Provide & 0 & 1 & 0 & 1 & 2 & 9 & 8 & 13 & 34 \\
\hline Determine & 5 & 1 & 5 & 4 & 1 & 1 & 6 & 11 & 34 \\
\hline Test & 1 & 5 & 8 & 2 & 6 & 5 & 2 & 5 & 34 \\
\hline Pull & 0 & 7 & 9 & 5 & 2 & 3 & 5 & 2 & 33 \\
\hline Perform & 7 & 3 & 3 & 0 & 7 & 3 & 6 & 4 & 33 \\
\hline Control & 3 & 0 & 3 & 4 & 4 & 4 & 8 & 6 & 32 \\
\hline Balance & 1 & 4 & 7 & 9 & 1 & 6 & 2 & 0 & 30 \\
\hline Total articles & 26 & 36 & 60 & 54 & 38 & 50 & 49 & 45 & 358 \\
\hline
\end{tabular}

a Each cell represents the total number of articles that used the specific relation. To be included in the table, the relation was required to appear in approximately 8 percent of the total articles from 1947 through 1975.

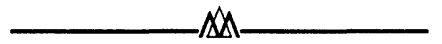

Christopher B. Bingham (cbingham@unc.edu) is an associate professor of strategy and entrepreneurship and the Phillip Hettleman Fellow at the Kenan-Flagler Business School, University of North Carolina at Chapel Hill. He received his $\mathrm{Ph}$.D. from Stanford University. His research interests focus on psychological foundations of organizations as well as learning, change, and strategy in entrepreneurial firms and in dynamic environments.
Steven J. Kahl (steven.j.kahl@tuck.dartmouth.edu) is an associate professor at the Tuck School of Business at Dartmouth. He received his Ph.D. from MIT. His research interests focus on the general question of emergencehow new products, organizations, and markets get created, gain legitimacy, and persist. 